\title{
In vitro Study of Apically Extruded Debris and Irrigant Following the Use of Conventional and Rotary Instrumentation Techniques
}

\author{
Elka Radeva and Vassileva Radosveta \\ Department of Conservative Dentistry, Faculty of Dental Medicine, Medical University, Sofia 1431, Bulgaria
}

\begin{abstract}
The complete preparation of the root canal space is one of the most important stages in endodontic treatment. While the root canal space is being prepared, debris, irrigant, necrotic tissue or bacteria may be extruded into the periapical region, leading to periapical inflammation and postoperative flare-ups. The aim of this study is to compare in vitro the amount of debris and irrigant extruded apically after a root canal preparation, using two instrumentation techniques- the conventional hand "step back" technique with SS K-files and the engine-driven "crown down” technique with Ni-Ti K3 files. Two groups of 20 extracted teeth with single canals were used. In group 1 (10 teeth), the root canals were instrumented using a “step back” technique and stainless steel K-files. In group 2 (10 teeth), the root canals were instrumented using a "crown-down” technique and nickel-titanium K3 rotary instruments. Debris and irrigant extruded from the apical foramen during instrumentation were collected into vials and the amounts were measured. The debris extruded through the apical foramen in group 1 (K-files) was $0.400 \mathrm{mg}$ and in group 2 (K3 files) - $0.225 \mathrm{mg}$. The volume of the extruded irrigant was $0.443 \mathrm{~mL}$ in group 1 and $0.247 \mathrm{~mL}$ in group 2 . The time taken for instrumentation was 13 min for the step back technique and $8.7 \mathrm{~min}$ for the crown-down technique. There is a significant difference in the amount of debris and irrigant produced between the two groups. During biomechanical preparation of the root canal space, debris and irrigant were extruded through the apical foramen by both instrumentation techniques.
\end{abstract}

Key words: Apical extrusion, step back technique, crown down technique.

\section{Introduction}

Apical extrusion of debris and irrigant during the cleaning and shaping of the root canal is one of the common problems encountered by the endodontist. The debris, which contains necrotic pulp and bacteria, initiate post-instrumentation inflammatory processes in the periapical region. Thus, it is necessary to look for a proper way to decrease the extrusion of debris via the periapical area in order to reduce post-treatment problems.

Various studies have attempted to quantify the amount of debris, irrigant and bacteria extruded beyond the apical foramen [1-5].

Moreover, many authors' researches support the

Corresponding author: Elka Radeva, Ph.D., assistant professor, research fields: endodontology, E-mail: eliradeva@abv.bg. statement that applying all techniques leads to production of debris extrusion into the periapical area, but to varying degree [6-9].

The aim of this study is to establish and compare in vitro the amount of debris and irrigant extruded apically, using two root canal instrumentation techniques - the conventional "step back" technique with SS K-files and the engine-driven "crown down" technique with Ni-Ti K3 files.

\section{Materials and Methods}

Twenty extracted teeth with single canals were used. All teeth had similar root curvatures of 0-10 degrees. The external surface of all teeth was cleaned with a periodontal curette. All teeth were controlled with digital radiographs in buccal and proximal directions to check for a single canal and one apical foramen. The 
teeth were stored in physiological saline solution.

The teeth crowns were cut at the ement-enamel junction and their length were standardised to $15 \mathrm{~mm}$. The working length was determined by means of electronic apex-locating device Raypex-5. All teeth were instrumented by a single practitioner.

The teeth were divided into two experimental groups of 10 teeth.

Group 1: Step back hand conventional technique (stainless steel K-files-Dentsply Maillefer, Switzerland)

The root canals in this group were instrumented using the "step back" technique to a size 35 file to the apical construction and a size 60 in coronal part of the teeth. Each file was used in push and pull motion until it was loose in the canal before the next size file was used. The apical preparation was enlarged to size 35 and then the larger files were used $1 \mathrm{~mm}$ shorter than the previous file. The file used to prepare the apical stop was applied to recapitulate. Distilled water was used as irrigant solution. Each canal was irrigated with $10 \mathrm{~mL}$ distilled water in total applying 27G 3/4 (0.4 × $19 \mathrm{~mm}$ ) needle.

Group 2: Crown down engine-driven technique (nickel-titanium K3 rotary instruments, Sybron Endo, USA)

The root canals in this group were instrumented using "crown down” technique and nickel-titanium K3 rotary instruments: Taper 0.08 -in the coronal part; Taper $0.06 / 25-1 / 2$ of working length; Taper $0.06 / 20$ - between $1 / 2$ and $2 / 3$ of working length; Taper $0.04 / 20, \quad 0.04 / 25, \quad 0.04 / 30, \quad 0.04 / 35$-full working length.

After each applied instrument the root canal was irrigated with distilled water. Each canal was irrigated with $10 \mathrm{~mL}$ distilled water in total applying 27G 3/4 $(0.4 \times 19 \mathrm{~mm})$ needle.

Control group-five vials of distilled water were used as a control measure. They were dried in the same way and weighed.

Time taken for each instrumentation technique was also determined.

Debris and irrigant extruded from the apical foramen during instrumentation were collected into vials (using the Myers and Montgomery technique) and the amounts were measured (Fig. 1).

The experimental model consisted of two glass vials, one of them larger, the other smaller (the smaller one was inside the larger one-but they were separate vials). The large vial was closed with a rubber plug, which was pierced, the opening corresponding to the root diameter of the tooth. The root of the tooth was placed in this opening and the surface was sealed with plastic.

During the processing of the root canals irrigant, debris passed through the apical foramen are collected in a small glass vial. This vial contained distilled water, and the apical part of the root was immersed in it. All vials were numbered and measured by the quantity of distilled water in them prior to the root canal processing.

Immediately after the canal instrumentation, the smaller vials were removed from the larger ones and measured. Then they were placed in an electric oven at a temperature of $50-60{ }^{\circ} \mathrm{C}$ for $12-24 \mathrm{~h}$ until the liquid had evaporated. All the tubes with vaporized liquid were placed in a desiccator containing $\mathrm{CaCl}_{2}$ in order to prevent absorption and measured three times with an analytical balance. The average of the measured values has been taken into consideration for the final result.

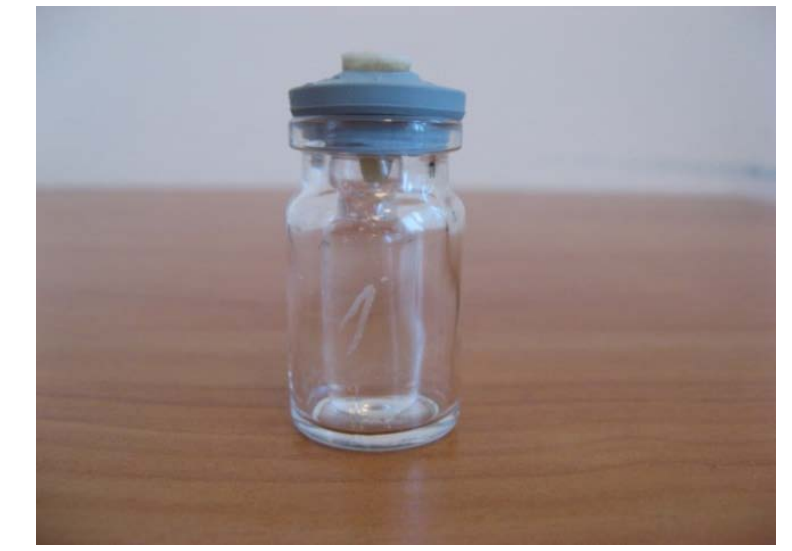

Fig. 1 Experimental model for collecting debris and irrigant during root canal preparation. 
The measurements were done with an analytical balance with an accuracy of five decimal places.

The data was input and processed using the statistical software package SPSS 17.0.1. The level of significance for rejecting the null hypothesis was fixed at $P<0.05$.

The following methods were applied:

(1) Analysis of variance-for calculating the estimates for the central tendency and dispersion;

(2) Graphical analysis_-for visualizing the obtained results;

(3) Shapiro-Wilk test-for checking the normality of distribution;

(4) Student's parametric test-for checking hypotheses of difference between two independent samples;

(5) Mann-Whitney nonparametric test-for checking hypotheses of difference between two independent samples.

\section{Results}

The data regarding the volume of irrigant and weight of debris extruded are presented in Table 1 and Figs. 2-4, respectively.

The conventional "step back" technique showed a greater extrusion of debris and irrigant than cleaning and shaping by the engine-driven technique with K3 Ni-Ti files.

The data revealed there showed a significant difference between the average of extruded debris and irrigant in hand and rotary techniques.

The amount of debris extruded through apical foramen by "step back" technique with stainless steel K-files was $0.400 \mathrm{mg}$. The volume of extruded irrigant was $0.433 \mathrm{~mL}$.

The amount of debris extruded through apical foramen by “crown down" technique with nickel-titanium K3 was $0.225 \mathrm{mg}$. The volume of extruded irrigant was $0.247 \mathrm{~mL}$.

Table 1 The weight of dry debris and irrigant extruded apically during cleaning and shaping by means of each technique.

\begin{tabular}{|c|c|c|c|c|c|}
\hline \multirow{3}{*}{ Index } & \multicolumn{4}{|c|}{ Technique } & \multirow{3}{*}{$P$} \\
\hline & \multicolumn{2}{|c|}{ “Step back” $(n=10)$} & \multicolumn{2}{|c|}{ "Crown down" $(n=10)$} & \\
\hline & $\overline{\mathrm{X}}$ & S.D. & $\bar{X}$ & S.D. & \\
\hline Weight of dry debris (mg) & 0.400 & 0.193 & 0.225 & 0.079 & 0.021 \\
\hline Weight of extruded irrigant (mL) & 0.433 & 0.154 & 0.247 & 0.098 & 0.005 \\
\hline Time taken for instrumentation (min) & 13.000 & 0.816 & 8.700 & 0.675 & $<0.001$ \\
\hline
\end{tabular}

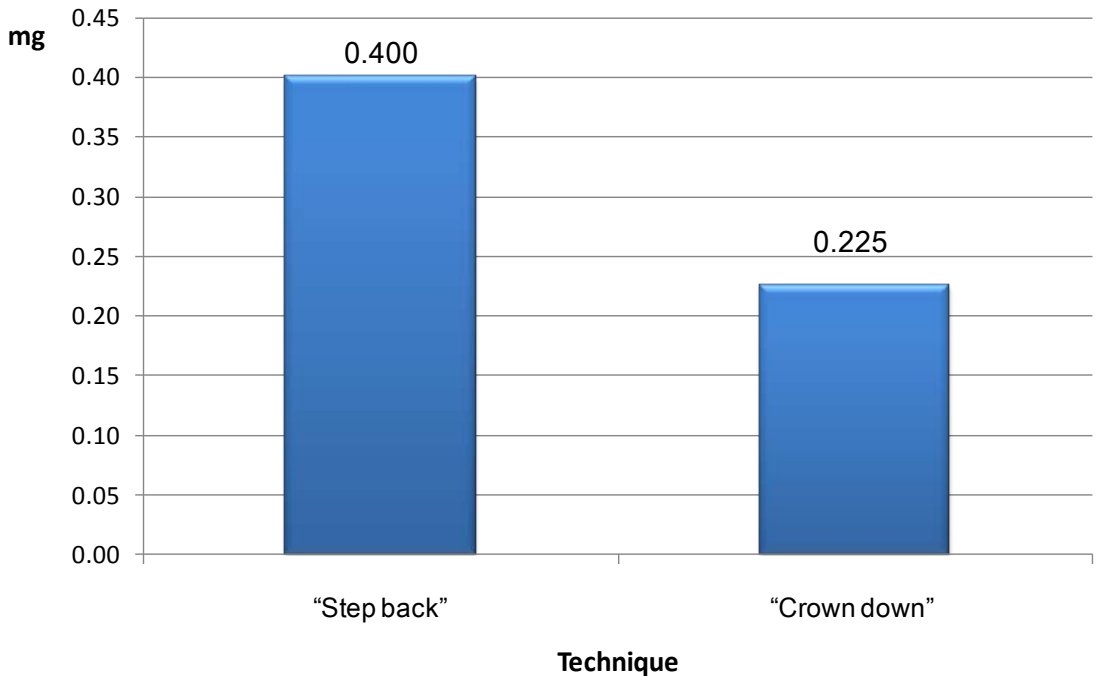

Fig. 2 Average extruded debris in "step back" and “crown down” techniques. 


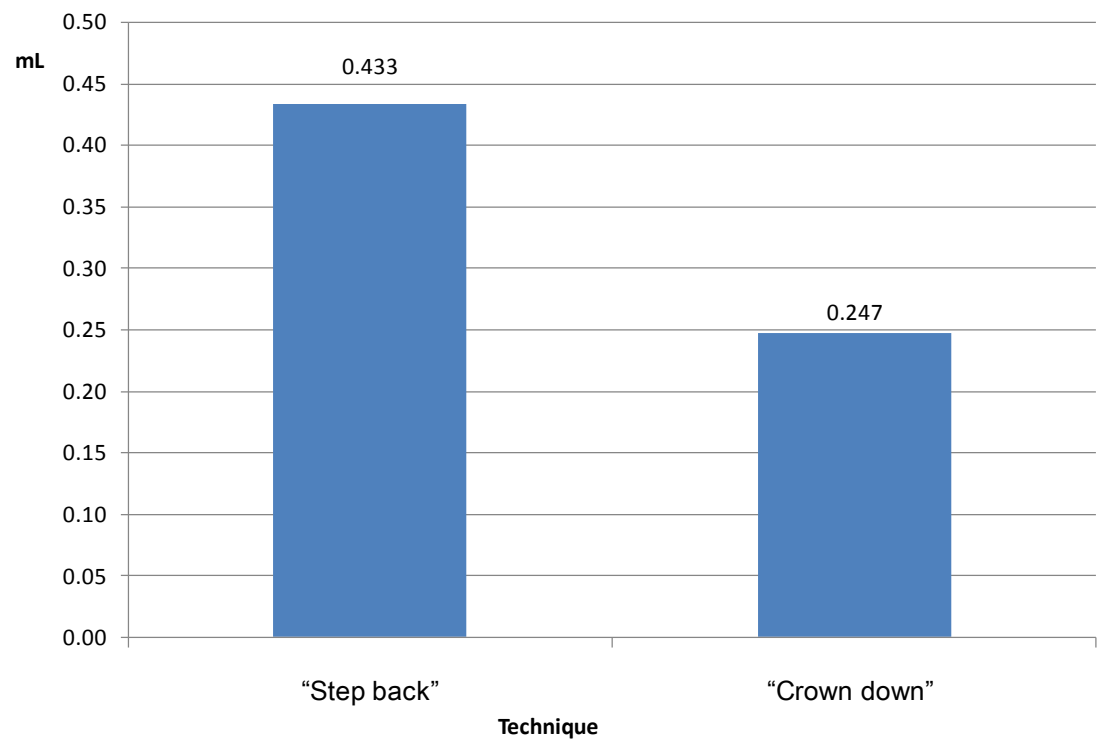

Fig. 3 Average extruded irrigant in "step back” and “crown down” techniques.

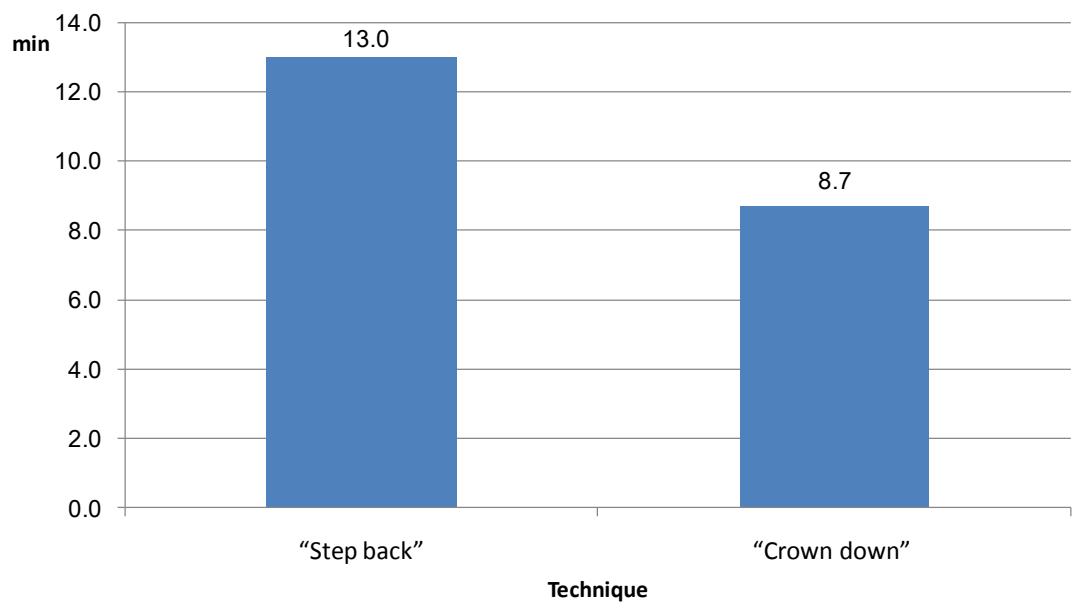

Fig. 4 Average time taken in the two techniques of canal instrumentation.

The results show that both techniques have produced extruded debris and irrigant through apical foramen. (Table 1 and Figs. 2-4). Significant differences can be observed in the amount of debris and irrigant produced between two groups.

The processing time for a root canal engine driven techniques is significantly less (8.7 min during treatment with $\mathrm{Ni}$-Ti K3-file) in comparison with conventional methods (13 min during step back hand technique).

\section{Discussion}

The main objective of the present study was to assess the apical extrusion of the debris and irrigant as a result of canal shaping by means of different preparation techniques and instruments.

The results presented here are consistent with those of other investigators and confirm the conclusion that linear filing motion extrudes more debris and irrigant. Some previous studies have shown that the initial coronal flaring and crown down techniques produce less apical extrusion [8-13]. Bidar et al. [10] confirmed that using a rotary technique is beneficial in decreasing the amount of debris extrusion to the periapical area, since, in the case of the rotary technique, debris is blocked in file flutes and moves to the coronal portion. 


\section{Instrumentation Techniques}

In group 1, where a step back technique is applied, the probable reason for more apical extrusion of debris is that the file acting in the apical one third as a piston which tends to push the debris through the foramen and less space is available to flush it out coronally.

In group 2, a crown-down technique is used by the K3 files. Despite being a 0.04 taper instrument, the extrusion of debris is due to its typical instrument design.

The rotation during instrumentation tended to pack the dentinal debris into the flutes of the files and directed them toward the orifice.

Kustarci et al. [2] compared three engine-driven techniques (RaCe, K3, FlexMaster) with each other and with the conventional step back technique. The obtained results have shown that the amount of extruded material in the step back technique is the largest and that it is the least when Ni-Ti RaCe rotary instruments are applied.

The application of engine-driven instruments and crown down technique for root canals leads to overcoming the disadvantages of the step back technique to a significant degree; namely an increased possibility of extrusion of the canal contents into the periapical area, inability to complete irrigation-solutions cannot reach the apical part-high probability of formation of ledges and plugs and a reduction of the working length [14].

The engine-driven technique has been shown to prepare the root canal more rapidly than applying hand technique. In in vitro studies, the tooth is suspended in air or vacuum, but in vivo it is surrounded by periapical tissues. One of the aims of the canal preparation should be to minimize the apical extrusion in order to prevent unwanted pain and inflammation. Therefore, it is logical to use a technique which minimizes this occurrence.

\section{Conclusions}

Measurable apical extrusion of debris and irrigant is produced during biomechanical preparation of the root canal space by conventional and engine-driven techniques.

A significant amount of extruded debris and irrigant is produced by the conventional step back technique.

A significant reduction in the amount of extruded debris and irrigant is obtained in the case of the crown down technique.

The engine-driven technique has been shown to be more rapid for preparing the root canal than the hand technique.

\section{References}

[1] A. Guelzow, O. Stamm, P. Martus, A. Kielbassa, Comparative study of six rotary nickel-titanium systems and hand instrumentation for root canal preparation, Int. Endod. J. 38 (10) (2005) 743-752.

[2] A. Kustarci, K.E. Akpinar, Er. Kursat, Apical extrusion of intracanal debris and irrigant following use of varios instrumentation techniques, Oral Surg. Oral Med. Oral Pathol. Oral Radiol. Endod. 105 (2) (2008) 257-262.

[3] A. Kustarci, K. Akpinar, Z. Zumer, K. Er, B. Bek, Apical extrusion of intracanal bacteria following use of various instrumentation techniques, Int. Endod. J. 41 (12) (2008) 1066-1071.

[4] Z. Mohammadi, In vitro evaluation of apical extrusion of bacteria following use of new rotary instrumentation system, N Y State Dent. J. 75 (3) (2009) 28-30.

[5] L.P. Vansan, J.D. Pécora, W.F. da Costa, R.G. Silva, R.N. Savioli, Comparative in vitro study of apically extruded material after four different root canal instrumentation techniques, Braz. Dent. J. 8 (2) (1997) 79-83.

[6] Z. Sumer, K. Akpnar, Apical extrusion of intracanal bacteria following use of two engine-driven instrumentation techniques, Int. Endod. J. 38 (12) (2005) 871-876.

[7] T. Lambrianidis, E. Tosounidou, M. Tzoanopoulou, The effect of maintaining apical patency on periapical extrusion, J. Endod. 27 (11) (2003) 696-698.

[8] M.H. Zarrabi, M. Bidar, H. Jafarzadeh, An in vitro comparative study of apically extruded debris resulting from conventional and three rotary (Profile, RaCe, Flexmaster) instrumentation techniques, J. Oral Sci. 48 (2) (2006) 85-88.

[9] C. Ferraz, N.V. Gomes, B.P. Gomes, A. Zaia, F. Teixeira, F. Filho, Apical extrusion of debris and irrigants using two hand and three engine-driven instrumentation techniques, Int. Endod. J. 34 (5) (2001) 354-358.

[10] M. Bidar, A.F. Rastegar, P. Ghaziani, M.S. Namazikhah, 


\section{Instrumentation Techniques}

Evaluation of apically extruded debris in conventional and rotary instrumentation techniques, J. Calif. Dent. Assoc. 32 (9) (2004) 665-671.

[11] S. Mangalam, C.V.N. Rao, L. Lakshminarayanan, Evaluation of apically extruded debris and irrigant using three instrumentation techniques, Endodontology 14 (2002) 19-23.

[12] L.E. Leonardi, D.M. Atlas, G. Raiden, Apical extrusion of debris by manual and mechanical instrumentation, Braz. Dent. J. 18 (1) (2007) 16-19.
[13] J. Tanalp, F. Kaptan, S. Sert, B. Kayahan, G. Bayirl, Quantitative evaluation of the amount of apically extruded debris using 3 different rotary instrumentation systems, Oral Surg. Oral Med. Oral Pathol. Oral Radiol. Endod. 2 101 (2) (2006) 250-257.

[14] S. Yancheva, E. Radeva, For some recent developments and issues in endodontics in the treatment of curved root canals. Third part-Hand techniques most commonly used for treatment of curved root canals, Zabolekarski Pregled 83 (1) (2001) 38-45. (in Bulgarian) 